\title{
THE PREPARATION OF WATER-OLIVE EMULSIONS FROM WASTE AND BY-PRODUCTS OF COKE- CHEMICAL PRODUCTION OF PJSC "YUZHKOKS" FOR ADJUNCTION TO COAL BLEND
}

(C) A.L. Borisenko, PhD in technical sciences, M.I. Bliznyukova, V.A. Panasenko, Doctor of Technical Sciences (State Enterprise "Ukrainian State Research Institute for Carbochemistry (UKHIN)", 7, Vesnina Str., 61023, Kharkiv, Ukraine)

The existing experience and results of previous studies for the production of emulsions from resinous waste and by-products of coke production has been analyzed.

A necessary condition for the creation of stable emulsion is the presence in its composition of three main components: diluent oil, emulsifiers and a neutralizing agent.

In order to determine the suitability of waste and by-products of production of PJSC "YUZHKOKS" as components of water-oil emulsions, the physicochemical characteristics of acid tar of ammonia capture, neutralized acid tar of rectification of crude benzene, resins and oils of biochemical plant, non-boiling residues of monoethanolamine desulfurization of coke oven gas, alkaline water, storage waste and coal tar has been studied. The ability of these materials to mix with each other has been also studied.

As a result of research, it has been found that the presents of coal tar in the composition of the diluent oil leads to the formation of more stable over time emulsions with low viscosity. The amount of coal tar in diluent oils should be 50-70\%. Non-boiling residues of monoethanolamine purification of coke oven gas from hydrogen sulfide proved to be a better neutralizing agent than alkaline water, in particular, for the reason that in some cases their use allowed to obtain homogeneous mixtures without delamination and separation of the aqueous layer by mixing emulsion components.

It has been shown that when emulsions preparing it is important to follow the order of mixing the components.

Based on the obtained data, formulations have been developed and the conditions for obtaining stable emulsions has been determined. Recommendations for obtaining emulsions for the purpose of their qualified use by feeding to the coal blend and improving the operation of the existing plant for waste and by-products utilization at the enterprise has been formulated.

Keywords: water-olive emulsions, coke production, waste, by-products, feeding into coal blend.

Author for correspondence: A.L. Borisenko; zd@ukhin.org.ua 